\title{
$\alpha$-Lipoic acid suppresses migration and invasion via downregulation of cell surface $\beta 1$-integrin expression in bladder cancer cells
}

\author{
Masao Yamasaki, ${ }^{1}$ Masahiro Iwase, ${ }^{1}$ Kazuo Kawano, ${ }^{1}$ Yoichi Sakakibara, ${ }^{1}$ Masahito Suiko, ${ }^{1}$ Masahiro Ikeda ${ }^{2}$ \\ and Kazuo Nishiyama ${ }^{1, *}$ \\ ${ }^{1}$ Department of Biochemistry and Applied Biosciences and ${ }^{2}$ Department of Veterinary Science, Faculty of Agriculture, University of Miyazaki, \\ 1-1 Gakuenkibanadai-nishi Miyazaki 889-2192, Japan
}

\begin{abstract}
Our previous study showed $\alpha$-lipoic acid (LA) downregulated cell surface $\beta 1$-integrin expression of $\mathrm{v}$-H-ras-transformed derivative of rat fibroblast with amelioration of their malignant phenotype. Here, we evaluated the ameliorating effect of LA on the malignant characters in H-ras-transformed bladder cancer cells. H-ras mutated bladder cancer line, T24 cells were incubated with LA to evaluate the inhibitory effect on proliferation, migration, invasion and $\beta 1$ integrin expression. Fluorescence staining of F-actin and western blotting analyses of the related signaling pathways were also performed. LA inhibited the proliferation of T24 cells. Cell adhesion to collagen IV and fibronectin was strikingly inhibited by LA treatment accompanied by downregulation of cell surface but not whole cell $\beta 1$-integrin expression. LA clearly inhibited cell migration and invasion of T24 cells, which were mimicked by extracellular signal-regulated kinase (ERK) and Akt pathway inhibition. Actually, LA significantly downregulated the phosphorylated ERK and Akt levels. Moreover, LA downregulated phosphorylated focal adhesion kinase level with disappearance of stress fiber formation. Finally, although LA induced the internalization of cell surface $\beta 1$-integrin, disruption of the raft did not affect the action of LA. Taken together, LA is a promising agent to improve malignant character of bladder cancer cells through regulation of cellular $\beta 1$-integrin localization.
\end{abstract}

Key Words: bladder cancer cells, $\alpha$-lipoic acid, invasion, migration, $\beta 1$-integrin

$\mathrm{R}$ as proteins are oncogene products capable of inducing cell transformation and are associated with many types of human cancer. Indeed, ras mutation is recognized in a broad range of human cancers. ${ }^{(1)}$ Wild-type Ras proteins play a central role in the regulation of normal cell proliferation, whereas activation mutation of Ras confers properties of cancer cells, such as deregulated proliferation, abnormal motility and differentiation. ${ }^{(2,3)}$ For instance, the HR-3Y1-2 cell line, derived from 3Y1 rat fibroblasts transformed with the v-H-ras oncogene, ${ }^{(4)}$ show anchorageindependent proliferation and changes in cellular morphology, ${ }^{(5)}$ and HR-3Y1-2 cells are capable of proliferating faster than the parental cell line $3 \mathrm{Y} 1{ }^{(6)}$ Therefore, a component that can suppress of activated Ras can be promising agent for alleviation of malignant characters of cancer cells. In our previous study in which we explored the components that was capable of suppressing the proliferation of HR-3Y1-2 cells, $\alpha$-lipoic acid (LA) was shown to selectively inhibit the proliferation of HR-3Y1-2 cells. ${ }^{(7)}$ Furthermore, LA potently suppressed the migration and invasion of HR3 Y 1-2 cells accompanied with downregulation of $\beta 1$-integrin expression. Therefore, LA is a promising agent for alleviation of malignant characters in ras mutated cancer cells.

LA is a naturally occurring antioxidative compound and is essential in humans, functioning as a coenzyme in various biological processes. Accumulating data have been revealed that LA has cytotoxic effect and migration inhibitory effect on cancer cells. $^{(8-11)}$ However, their detail molecular mechanisms are not fully understood. Frequency of mutation of ras family such as $\mathrm{H}-$ ras, $\mathrm{K}-$ ras and N-ras in human tumors is highly organ specific and H-ras mutation is common in bladder cancer. ${ }^{(12,13)}$ Here, we evaluated the effect of LA on the proliferation, migration and invasion of bladder cancer cells. Moreover, involvement of $\beta 1$ integrin in the action of LA was also evaluated.

\section{Materials and Methods}

Chemicals. LA was purchased from Sigma (St. Louis, MO). PD98059 was purchased from Biomol Research Laboratories (Plymouth Meeting, PA) and LY294002 was purchased from Cell Signaling Technology (Beverly, MA). Methyl- $\beta$-cyclodextrin was purchased from Tokyo Chemical Industries (Tokyo, Japan).

Cell culture. T24 human bladder cancer cell line was purchased from the Japanese Collection of Research Bioresources (JCRB0711, Osaka, Japan). Cells were maintained in Dulbecco's modified Eagle's medium (DMEM) supplemented with 10\% fetal bovine serum (FBS) containing 100 units $/ \mathrm{ml}$ of penicillin $\mathrm{G}$ and $100 \mu \mathrm{g} / \mathrm{ml}$ of streptomycin. Cells were subcultured twice a week, and in actual in vitro experiments, the cells were seeded at $3.5 \times 10^{3}$ cells $/ \mathrm{cm}^{2}$ in $90-\mathrm{mm}$ dishes or 24 -well multiwell culture plates.

Cell adhesion to fibronectin. Cells at growth phase were treated with FBS-free DMEM for $60 \mathrm{~min}$ at $37^{\circ} \mathrm{C}$. The cells pretreated with or without LA were then recovered and seeded at $2.0 \times 10^{5}$ cells/well in fibronectin-coated or collagen IV-coated 24-well plates (BD Biosciences, San Jose, CA). After 60 min, floating cells were removed from the well and adherent cells were counted.

Western blotting analysis. At the end of the culture period, cells were lysed in $50 \mathrm{mM}$ Tris- $\mathrm{HCl}(\mathrm{pH} 7.5)$ containing $150 \mathrm{mM}$ $\mathrm{NaCl}, 2 \%$ Triton X-100, $2 \mathrm{mM}$ EDTA, $50 \mathrm{mM} \mathrm{NaF}, 30 \mathrm{mM}$ $\mathrm{Na}_{4} \mathrm{P}_{2} \mathrm{O}_{7}$, and $1 / 50$ vol. protease inhibitor cocktail (Nacalai Tesque, Kyoto, Japan). Protein concentrations were measured using the BCA protein assay reagent (Pierce, Rockford, IL). Lysates containing $10 \mu \mathrm{g}$ of protein were separated by electrophoresis on $10 \%$ SDS-polyacrylamide gels, and transferred onto

*To whom correspondence should be addressed. E-mail: nishiyam@cc.miyazaki-u.ac.jp 
PVDF Hybond-P membranes (Amersham-Pharmacia Biotech, Buckinghamshire, UK). Blocking was performed using $3 \%$ defatted milk in Tris-buffered saline with $0.1 \%$ Tween-20 (TTBS), and antibodies were diluted in Can Get Signal solutions 1 and 2 (Toyobo, Tokyo, Japan). Anti- $\beta 1$-integrin $(\mathrm{N}-20)$ and horseradish peroxidase-conjugated donkey anti-goat IgG were purchased from Santa Cruz Biotechnology (Santa Cruz, CA). Anti-extracellular signal-regulated kinase (ERK), anti-Akt, and anti-phosphorylated focal adhesion kinase (FAK) antibodies were purchased from Cell Signaling Technology and anti-FAK antibody was purchase form Assay Bio Technology (Sunnyvale, CA). The membranes were washed with TTBS after each antibody binding reaction. Detection of each protein was performed using an ECL Prime kit (Amersham-Pharmacia).

Cell surface $\beta 1$-integrin expression. At the end of the culture period, cells were washed with cold phosphate buffered saline (PBS), then incubated with FITC-conjugated anti- $\beta 1$ integrin (Santa Cruz Biotechnology) for $30 \mathrm{~min}$ at $4^{\circ} \mathrm{C}$. Cells were washed and resuspended into $2 \%$ FBS, 2 mM EDTA/PBS and subjected flow cytometric analysis (EPICS XL, Beckman Coulter, Fullerton, CA). Cells were stained with $10 \mu \mathrm{g} / \mathrm{ml}$ propidium iodide to eliminate dead cell from analysis.

Cell migration. Cells were cultured to confluence and dish bottom was scratched with plastic $200 \mu \mathrm{l}$ tip to remove the cells. Then, cells were cultured with serum-free media containing LA or inhibitors for 3-12 h. After taking photographs of scratched area, area of migrated cells was calculated to evaluate the migration. The extent of migration was measured by calculating the area occupied by the cells in a scratched area, the data showing $100 \%$ when the scratched area was completely filled with migrated cells.

Cell invasion. Cells were pretreated with LA or inhibitors for indicated time and concentration, and additionally incubated with FBS free medium for $2 \mathrm{~h}$. Then, cells suspended into FBS-free media were inoculated into matrigel coated cell insert chamber 24-well transwell chamber ( $8 \mu \mathrm{m}$ pore size). Lower chamber of transwell was filled with the DMEM with 5\% FBS. At the end of culture period, transwells were removed from 24-well plate, then lower surface was treated with $0.25 \%$ trypsin-EDTA and migrated cells were counted.

Fluorescence staining. Cells were cultured and treated with LA in glass bottom dish. At the end of culture period, cells were fixed with $4 \%$ paraformaldehyde for $10 \mathrm{~min}$ at room temperature. Then, cell membrane was permeabilized using $0.5 \%$ Triton-X100/ PBS for 5 min. F-actin was stained using commercial kit (Actistain 488, Cytoskelton, Denver, CO) according to the appended protocol. For immunostaining, after cell permeabilization, blocking was performed using $10 \%$ bovine serum albumin/PBS for $20 \mathrm{~min}$. Thereafter, cells were stained with FITC-conjugated anti- $\beta 1$ - integrin (Santa Cruz Biotechnology), and finally, nuclei were stained with Hoechst 33342 (Dojindo, Kumamoto, Japan).

Statistical analysis. Statistical analysis was done with 4 Steps Statcel2 software (OMS Publishing, Saitama, Japan). Data were analyzed by the Tukey-Kramer test, and differences at $p<0.05^{*}, 0.01 * *$ were considered significant.

\section{Results}

First, we evaluated the effects of LA on the growth of T24 cells. The results indicated that 0.3 and $1.0 \mathrm{mM}$ LA significantly prevented the growth of T24 cells at 24 and $48 \mathrm{~h}$. (Fig. 1A and B).

As LA inhibited the proliferation of T24 cells as previously shown in v-H-ras transformed rat fibroblast, we next evaluated the effects of LA on $\beta 1$-integrin expression and $\beta 1$-integrin related cell adhesion. As shown in Fig. 2A and B, western blotting data showed LA did not affect whole cell integrin level at each time point $(1.0 \mathrm{mM})$. On the other hand, flowcytometric analysis showed that LA dose-dependently downregulated cell surface integrin- $\beta 1$ expression, whereas no obvious time-dependency was detected during 12-48 h (Fig. 2C and D). To know whether downregulation of cell surface integrin- $\beta 1$ evokes a substantial decrease of cell adhesion to extracellular matrixes (ECMs), we examined the effect of LA on cell adhesion to collagen IV and fibronectin both of which are known to bind with integrin composed of $\beta 1$ subunit. Adhesion to these ECMs are significantly inhibited by $48 \mathrm{~h}$ pretreatment with 0.3 and $1.0 \mathrm{mM}$ or by 24 and $48 \mathrm{~h}$ pretreatment with $1.0 \mathrm{mM}$ LA (Fig. 2E and F).

Integrin mediated cell adhesion activates FAK and following polymerization of G-actin. F-actin, a polymerized G-actin, filament bundle is component of stress fiber that provides a tension and contraction to the cells and regulates cell motility. Next, we tried to know the effect of LA on FAK activation and stress fiber formation. As shown in Fig. 3A and B, LA downregulated phosphorylated FAK level. When cells were treated with $1.0 \mathrm{mM} \mathrm{LA}$, phosphorylated FAK level was significantly decreased at 12, 24 and 48 h. In Fig. 3C, F-actin was stained with phalloidin and shown in green color. Here, structured stress fiber was observed in the control cells, whereas cellular edge was clearly stained and obvious stress fiber was not observed in LA treated cells.

As stress fiber formation is an important driving force for cell motility, LA is expected to inhibit cell migration and invasion of T24 cells. As shown in Fig. 4A and B, wounding assay revealed T24 cells without any treatment actively migrated during $12 \mathrm{~h}$ assay period. In this wounding assay, cells were co-cultured with shown concentrations of LA during cell migration. LA dosedependently inhibited cell migration, and representative photographs (Fig. 4A) and Fig. 4B showed $1.0 \mathrm{mM} \mathrm{LA}$ treatment
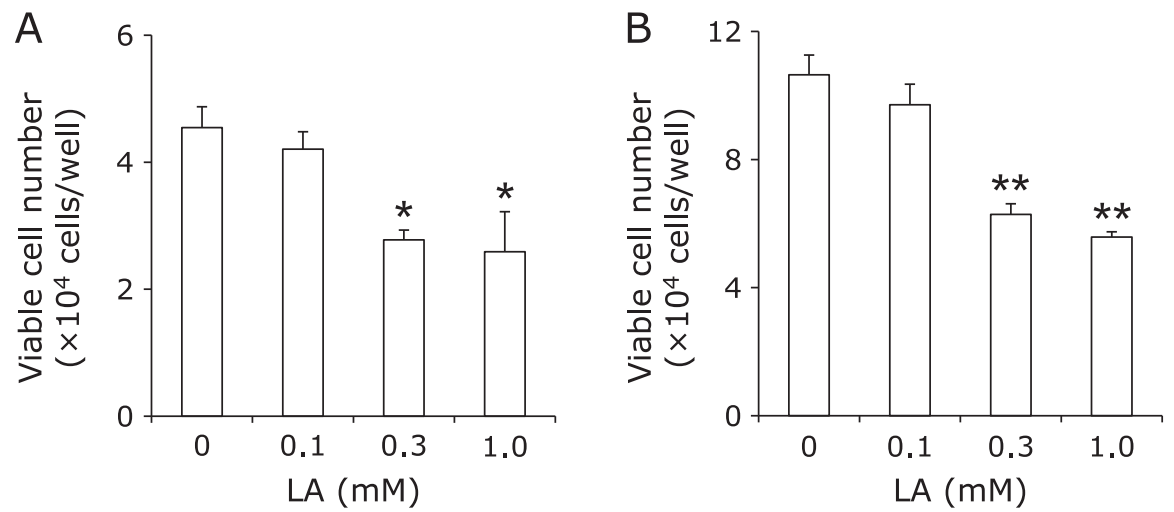

Fig. 1. Effects of $\alpha$-lipoic acid on proliferation of T24 cells. Cells were treated with $0,0.1,0.3,1.0 \mathrm{mM} \alpha$-lipoic acid for $24 \mathrm{~h}$ (A) and $48 \mathrm{~h}$ (B). Results are means \pm SD of 3 samples. Values marked with asterisk(s) are significantly different from the control value at $* p<0.05$ and $* \star p<0.01$, respectively. 
A
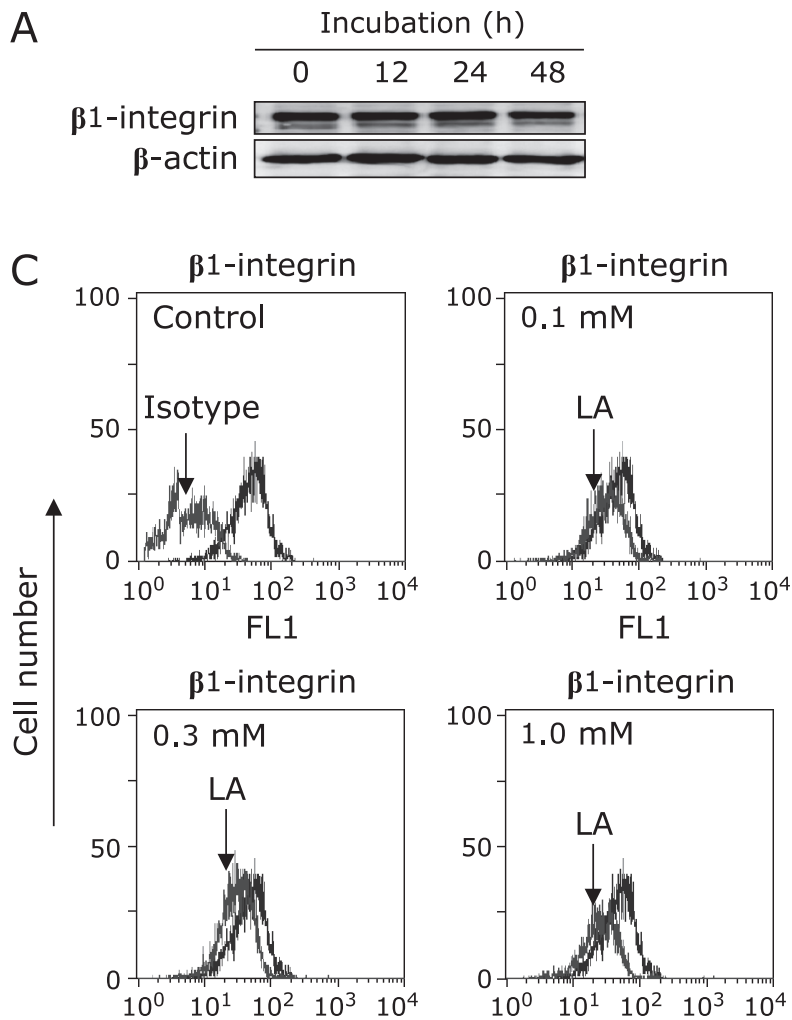

FL1

$\beta 1$-integrin expression
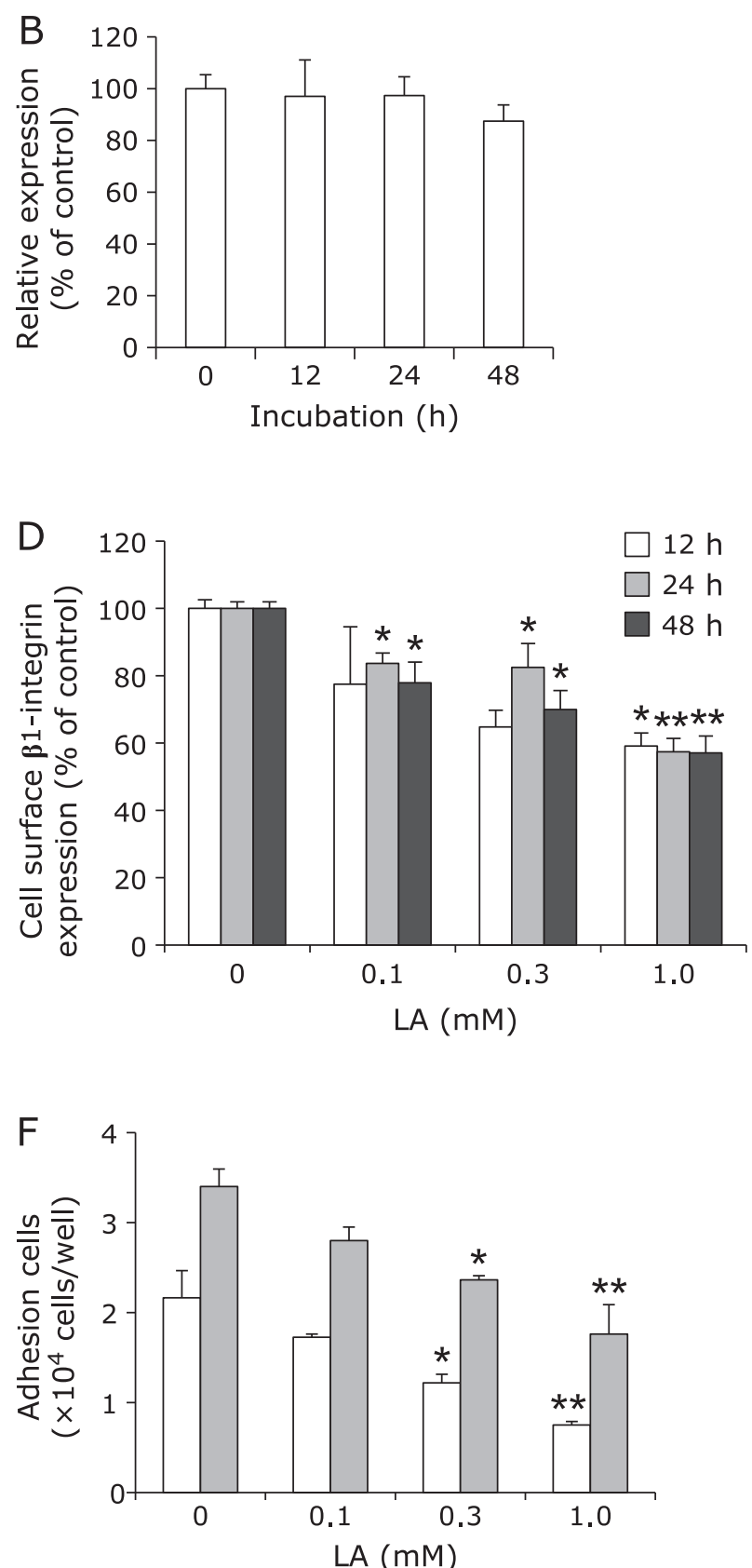

Fig. 2. $\alpha$-lipoic acid reduces cell surface $\beta 1$-integrin level and suppresses adhesion to collagen IV and fibronectin. (A, B) Effect of $\alpha$-lipoic acid (LA) $(1.0 \mathrm{mM})$ on the whole cell $\beta 1$-integrin expression was evaluated and representative band pattern was shown in $A$ and expression intensity was quantified in B ( $\beta 1$-integrin/ $\beta$-actin). (C, D) Effect of LA (1.0 mM) on the cell surface $\beta 1$-integrin expression was evaluated and representative histograms were shown in C and expression intensity was quantified in D. (E, F) Effect of cell adhesion to collagen IV (col IV) or fibronectin (Fn) on T24 cells. Cells were pretreated with $1.0 \mathrm{mM}$ LA for $12,24,48 \mathrm{~h}(\mathrm{E})$ or with $0,0.1,0.3,1.0 \mathrm{mM}$ LA for $48 \mathrm{~h}$ then, seeded onto collagen IV or fibronectin coated plates. Results are means \pm SD of 3 samples. Values marked with asterisk(s) are significantly different from the control value at ${ }^{*} p<0.05$ and ${ }^{*} p<0.01$, respectively.

almost completely inhibited the migration of T24 cells. Moreover, invasion assay revealed that 0.3 and $1.0 \mathrm{mM}$ LA pretreatment significantly inhibited T24 cell invasion ability at 24 and $48 \mathrm{~h}$ (Fig. 4C).

It is well-known that FAK activation leads to activation of its downstream signaling cascade ERK and Akt pathways that play pivotal role in regulating cell motility. We next tried to know the effect of LA on the phosphorylation of ERK and Akt. In addition, to know whether these inhibitors of these pathways mimics LA activity or not, PD98059, an MEK1 inhibitor, and
LY294002, and phosphatidylinositol-3 kinase (PI3K) inhibitor, were used. As a result, LA decreased phosphorylated ERK at 0.3 and $1.0 \mathrm{mM}$, and also decreased phosphorylated (Ser473 and Tyr308) Akt at $1.0 \mathrm{mM}$ (Fig. 5A, B, C and D). As shown in Fig. 5E, $40 \mu \mathrm{M}$ PD98059 and LY294002 strikingly inhibited cell invasion of T24 cells which was comparable to that of LA. Moreover, these inhibitors significantly inhibited cell migration of T24 cells. Although, at $3 \mathrm{~h}$ treatment, inhibition ability was comparable among PD98059, LY294002 and LA, LA exerted the strongest ability at 6 and $12 \mathrm{~h}$ (Fig. 5F). Furthermore, these inhibitors 

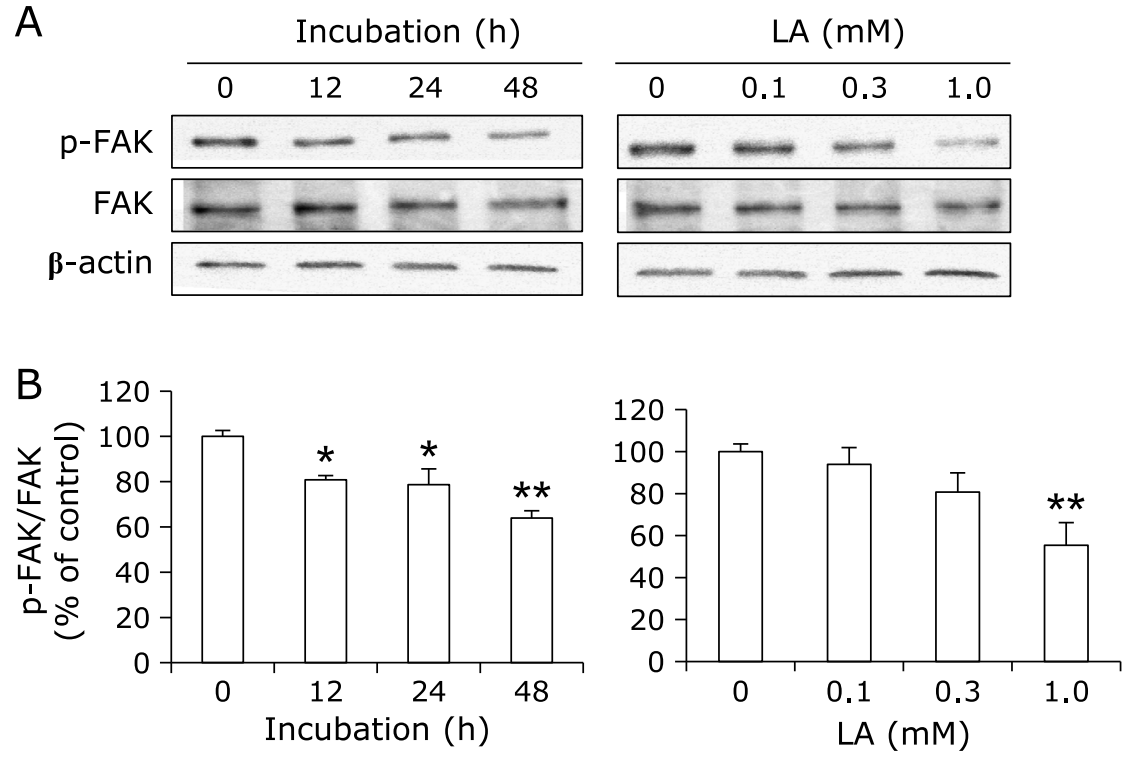

C
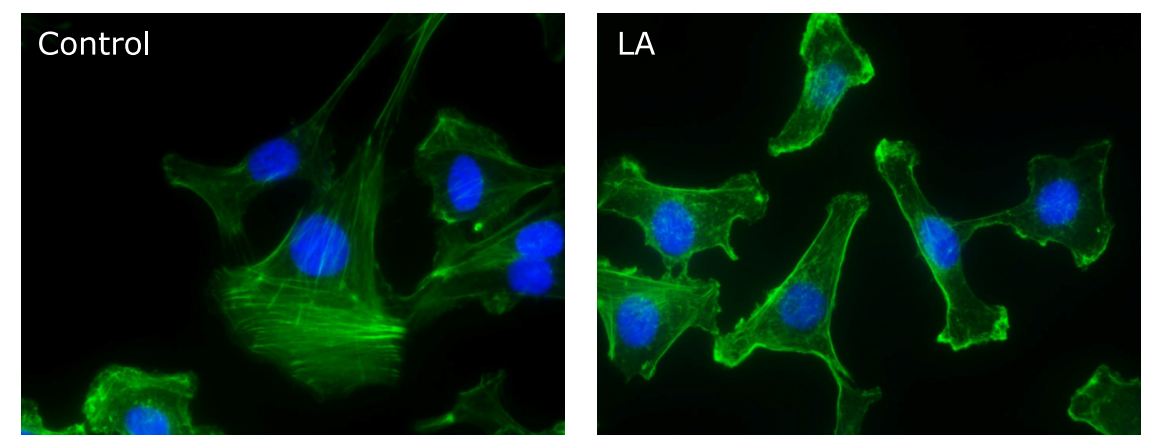

Fig. 3. Downregulation of phosphorylated focal adhesion kinase and stress fiber formation. (A, B) Effect of $\alpha$-lipoic acid (LA) on phosphorylated focal adhesion kinase (FAK) level was evaluated. In left panel, LA was $1.0 \mathrm{mM}$ and in right panel cells were treated for $48 \mathrm{~h}$. Representative band pattern was shown in A and expression intensity was quantified in B (p-FAK/FAK). (C) Cells were treated with 0 or $1.0 \mathrm{mM}$ LA for $48 \mathrm{~h}$ and actin fiber was stained with Acti-stain 488 (green) and nucleus were stained with Hoechst 33342 (blue). Results are means \pm SD of 3 samples. Values marked with asterisk(s) are significantly different from the control value at ${ }^{*} p<0.05$ and ${ }^{* *} p<0.01$, respectively.

were capable of downregulating cell surface $\beta 1$-integrin (Fig. 5G).

As shown in Fig. 2, although LA downregulated cell surface $\beta 1$-integrin level, whole cell $\beta 1$-integrin level was not changed. Here, we hypothesized that LA regulated $\beta 1$-integrin localization and promoted its internalization. Therefore, $\beta 1$-integrin localization was examined in membrane permeabilized cells. Interestingly, whereas $\beta 1$-integrin was uniformly distributed in cytosol fraction, deeply stained particles by $\beta 1$-integrin antibody was observed in LA treated T24 cells, showing concentration into this particle and internalization of $\beta 1$-integrin under LA treatment (Fig. 6A). To know whether this phenomenon of $\beta 1$-integrin is raft dependent or not, cells were treated with methyl $\beta$-cyclo dextrin $(\mathrm{M} \beta \mathrm{CD})$ which removes cholesterol from plasma membrane resulting in degradation of raft structure. As shown in Fig. 6B, $\mathrm{M} \beta C D$ did not affect on $\beta 1$-integrin level under LA treatment.

\section{Discussion}

Oncogenic mutations in H-ras are commonly found in bladder cancer and could be a molecular target of bladder cancer therapy. ${ }^{(13-17)}$ Actually, T24 cells used in this experiment possesses mutation in H-ras gene. ${ }^{(18)}$ This mutation evokes activation of Ras dependent signaling such as disregulated proliferation, abnormal cell adhesion and motility that are associated with cancer cell malignancy. Expression of these malignant phenotypes is associated with abnormal regulation of cellular integrin expression and activity. Our previous study revealed that cell surface $\beta 1$-integrin was upregulated accompanied with elevation of cell adhesion to fibronectin, cell migration and invasion in H-ras transformed $3 \mathrm{Y} 1$ fibroblasts. $^{(7)}$ In addition, several studies indicated that bladder cancer cells highly expressed $\beta 1$-integrin and blocking antibody for $\beta 1$-integrin prevented cell adhesion and cell migration in T24 cells. ${ }^{(18-21)}$ These data suggest that upregulated $\beta 1$-integrin expression plays an important role in the H-ras mediated expression of malignant character of cancer cells. Present data revealed that LA suppressed cell surface $\beta 1$-integrin expression in T24 cells without any change in whole cell expression. Integrin is a heterodimer molecule that consist of several $\alpha$ - and $\beta$-chains and binds to various ECM partners depend on a combination of $\alpha$ - and $\beta$ chain. (22) $\beta 1$-integrin forms heterodimeric complex with various $\alpha$-chain to bind variety of ECMs such as collagen IV and fibronectin. Data showed that cell adhesion to fibronectin and collagen IV was suppressed under LA treatment suggesting downregulation of cell surface $\beta 1$-integrin expression substantially attenuate cell adhesion to these ECMs.

Cell invasion requires cell migration and adhesion to ECM through integrins. During cell invasion, cancer cell form small projections called invadopodia that is rich in actin and plays a 
A
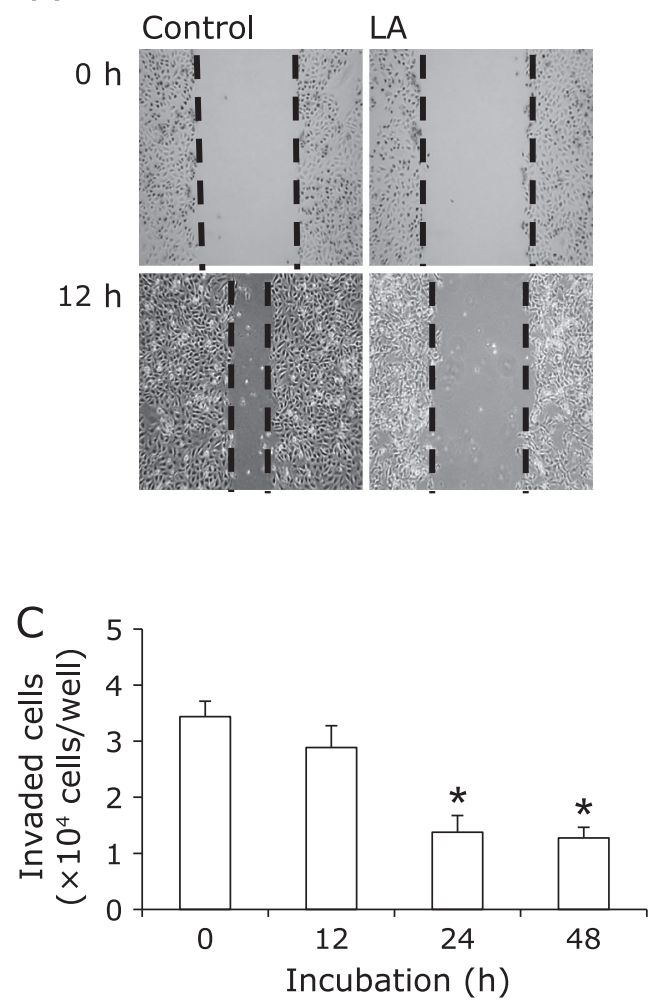

B
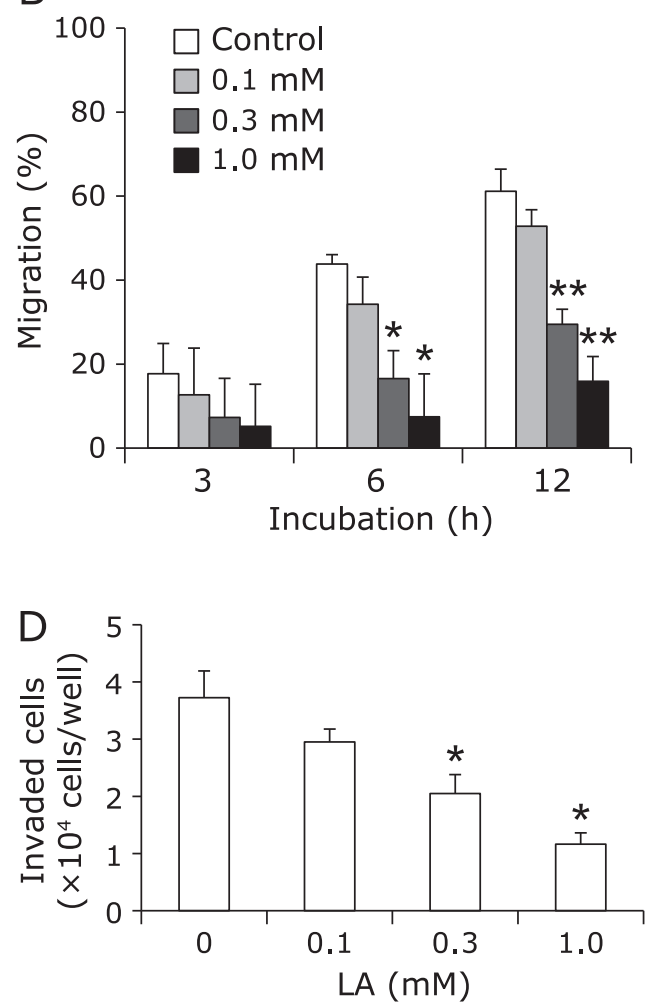

Fig. 4. Migration and invasion inhibition by $\alpha$-lipoic acid. (A, B) Wounding assay was performed for the evaluation of cell migration. During migration for 3,6 and $12 \mathrm{~h}$, cells were treated with shown concentrations of $\alpha$-lipoic acid (LA). The extent of migration was measured by calculating the area occupied by the cells in a scratched area, the data showing $100 \%$ when the scratched area was completely filled with migrated cells. A shows the representative migration pattern of cells treated with or without LA. (C, D) Cell invasion was evaluated. Cells were pretreated with 1.0 mM LA for $12,24,48 \mathrm{~h}(\mathrm{C})$ or with $0,0.1,0.3,1.0 \mathrm{mM}$ LA for $48 \mathrm{~h}$ (D). Results are means \pm SD of 3 samples. Values marked with asterisk(s) are significantly different from the control value at ${ }^{\star} p<0.05$ and ${ }^{*} p<0.01$, respectively.

pivotal role in cell motility. $\beta 1$-Integrin is highly localized into invadopodia. ${ }^{(23,24)}$ Actually, in bladder cancer cells, $\alpha 5 \beta 1$ integrin plays a pivotal role in cell invasion through generation of contractile forces that provide cells a driving force of cell movement. ${ }^{(25)}$ Data in this study show that LA suppressed migration and invasion accompanied with downregulation of cell surface $\beta 1$-integrin. Therefore, it is reasonable to support that inhibition of cell adhesion, migration and invasion is attributable to downregulation of cell surface $\beta 1$-integrin expression. Suppression of matrix metalloproteinase (MMP) family may be involved in invasion suppression of T24 cell, because it has been reported that LA suppressed invasion and expression of MMP-2, -9 in human breast cancer cells, MDA-MB-231 cells that possess K-ras mutation. ${ }^{(11)}$

Here, substantial effect of downregulation of cell surface $\beta 1$ integrin expression on integrin-related signal was also evaluated. FAK, a tyrosine kinase, binds to intracellular domain of integrin and binding of $\beta 1$-integrin with ECMs occurs its autophosphorylation at Tyr397.(26) As shown in Fig. 3, LA decreased phosphorylated FAK level, suggesting substantial attenuation of integrin signaling. As LA and dihydro-LA downregulates cell surface expression of the $\alpha 4, \beta 1$-integrin in human Jurkat $\mathrm{T}$ cells, and intercellular adhesion molecule 1 and vascular cell adhesion protein 1 in central nervous system endothelial cells, LA might dynamically regulate cell surface protein expressions in several types of cells. ${ }^{(27,28)}$ FAK phosphorylation by integrin engagement triggers activation of downstream signal cascades such as ERK and PI3K/Akt pathway and resulting in upregulation of MMPs expression and regulation of RhoA, $\mathrm{Cdc} 42$, Racl pathway that evokes cell migration, invasion and proliferation. ${ }^{(29-33)}$ As present data show that LA decreased phosphorylated ERK1/2 and Akt levels, suggesting attenuation of ERK and PI3K/Akt pathway was caused by downregulation of cell surface integrin- $\beta 1$ and FAK phosphorylation. In addition, actin stress fiber formation provide cellular tensile and contractile force that enable cell motility. Stress fiber formation is regulated by RhoA which is activated by integrin signaling pathway. ${ }^{(34)}$ Therefore, downregulation of phosphorylated FAK and stress fiber formation by LA shown in Fig. 3B strongly suggests the substantial inhibition of integrin signaling. Moreover, inhibitors for ERK and Akt pathways mimicked the action of LA in that they inhibited inhibition and migration of T24 cells (Fig. 4). Therefore, it is considered that ERK and Akt pathways are responsible for migration and invasion suppression by LA.

Schwartz et al. ${ }^{(35)}$ have shown that LA significantly inhibited the growth of T24 cells and Fig. 1 supports this previous data. Although proliferation inhibition of bladder cancer cells was also observed in vivo mice transplanted model, ${ }^{(36)}$ there is no evidence of relationship between proliferation inhibition and downregulation of $\beta 1$-integrin expression. ERK and PI3K/Akt pathway are pivotal regulator for cell proliferation in bladder cancer, besides inhibition of these pathway evokes growth inhibition of bladder cancer cells. ${ }^{(37)}$ Therefore, downregulation of ERK and PI3K/Akt pathway might contribute to the growth inhibitory effect of LA on T24 cells shown in Fig. 1. Moreover since LA suppressed of platelet derived growth factor induced ras related ERK signaling in vascular smooth muscle cells and transforming growth factor- $\beta$ induced ERK phosphorylation, ${ }^{(38,39)}$ LA might downregulate ras related ERK activation in T24 cells. 
A

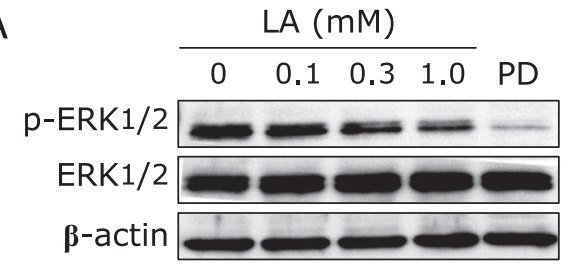

C
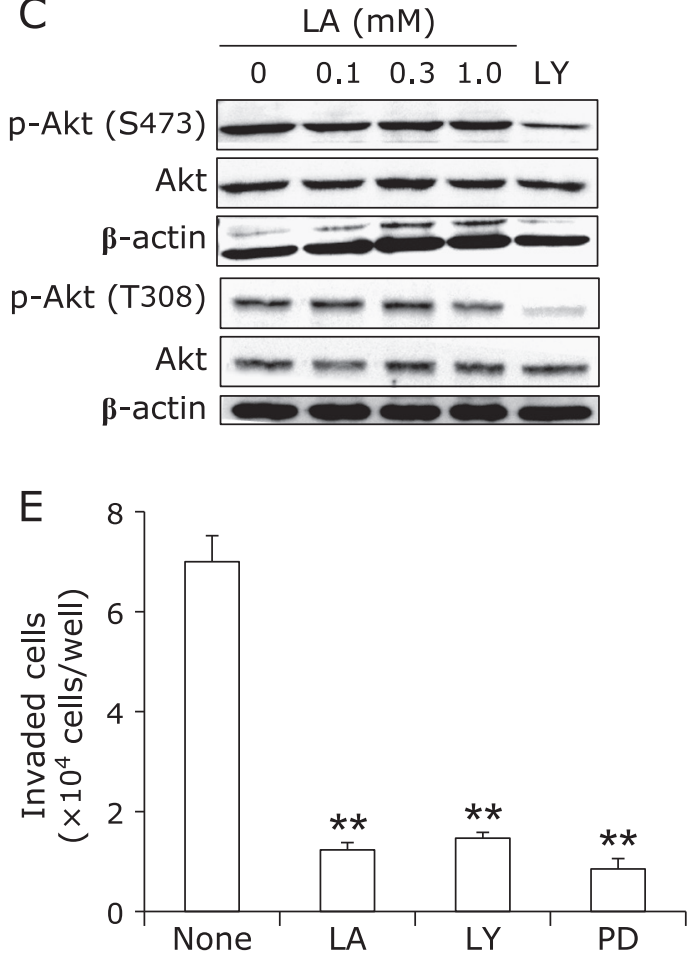

$\mathrm{B}$
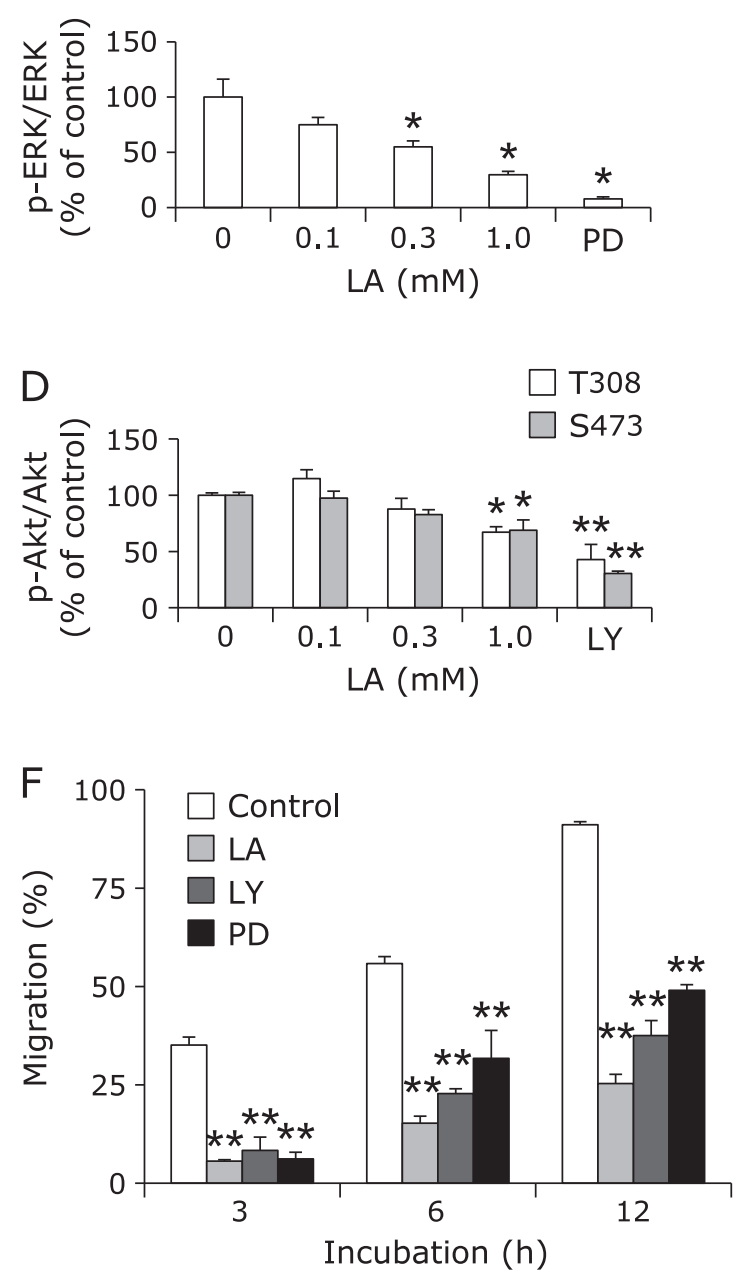

Fig. 5. Effect of $\alpha$-lipoic acid on the activities of extracellular signal-regulated kinase and akt pathway. (A-D) Effect of $\alpha$-lipoic acid (LA) on phosphorylated extracellular signal-regulated kinase (ERK) (A, B) and Akt (C, D) level was evaluated. Cell were treated with $0,0.1,0.3$ and 1.0 mM LA for $48 \mathrm{~h}$. Representative band patterns were shown in $A$ and $C$ and expression intensity was quantified in $B, D$ (p-ERK/ERK or $p-A k t / A k t)$. (E, F) Invasion and migration inhibition by ERK and Akt inhibitors. Cells were pretreated with $1.0 \mathrm{mM}$ LA, $40 \mu \mathrm{M}$ LY294002 (LY) or $40 \mu \mathrm{M}$ PD98059 (PD) for $24 \mathrm{~h}$ and cell invasion was evaluated (E). During migration for 3, 6 and $12 \mathrm{~h}$, cells were treated with $1.0 \mathrm{mM}$ LA, $40 \mu \mathrm{M}$ LY294002 or $40 \mu \mathrm{M}$ PD98059 (F). Cell surface $\beta 1$-integrin expression was evaluated in cells treated with $1.0 \mathrm{mM}$ LA, $40 \mu \mathrm{M}$ LY294002 or $40 \mu \mathrm{M}$ PD98059 for $24 \mathrm{~h}$. Results are means \pm SD of 3 samples. Values marked with asterisk(s) are significantly different from the control value at * $p<0.05$ and $* * p<0.01$, respectively.

Akt and ERK pathways are representative signaling route from Ras and these pathways are responsible for regulating integrinligand binding affinity. ${ }^{(40,41)}$ Therefore, integrin related pathway and Ras related pathway closely overlap and interact each other. It is considered that LA at least suppressed integrin related pathway because cell surface integrin level and adhesion to fibronectin and collagen IV were inhibited in T24 cells. On the other hand, it is unclear whether suppression of cell surface $\beta 1$-integrin expression is sufficient to explain the adhesion inhibition because integrin activity is regulated by its conformational change as well as transcriptional, translational and cellular localization level. ${ }^{(42)}$ Moreover, in the case of bladder cancer cells, oligosaccharide pattern of $\alpha 3 \beta 1$ integrin is critical factor for determining affinity to fibronectin and cell migration. ${ }^{(43)}$

Integrins abundantly exist on the lipid raft regions of plasma membrane where several signaling molecules that participate in the integrin signaling are recruited in response to integrin engagement to ECM. ${ }^{(44-48)}$ Such localization on plasma membrane is regulated by intracellular membrane transport related proteins such as Arf/Sar family and Rab family via regulation of endo- cytosis and exocytosis. ${ }^{(49,50)}$ Coming-in and coming-out of integrin from plasma membrane to cytosolic fraction is called integrin trafficking that is the plausible target of LA because LA downregulated cell surface $\beta 1$-integrin level without any change in whole cell integrin level. Microscopic data clearly showed the particles of integrin in LA treated cells, indicating occurrence of integrin trafficking. Endocytotic mechanism of integrin is still controversial but two major pathways are proposed. One is clathrin-mediated and other is raft-mediated pathway, ${ }^{(51-54)}$ and latter pathway is prevented by depletion of cholesterol from the raft using $\mathrm{M} \beta \mathrm{CD} .^{(55)}$ As $\mathrm{M} \beta \mathrm{CD}$ treatment of $\mathrm{T} 24$ cells did not change integrin localization in T24 cells, raft dependent integrin internalization seems not occur robustly at steady state. In addition, $M \beta C D$ treatment did not interfered the action of LA. Taken together, it is considered that LA suppressed cell surface $\beta 1$ integrin via raft independent internalization and further studies are needed to clarify the involvement of other endocytosis pathway and exocytosis.

Although several reports have been revealed that LA induced apoptotic cell death and inhibited cell migration in cancer cells, 

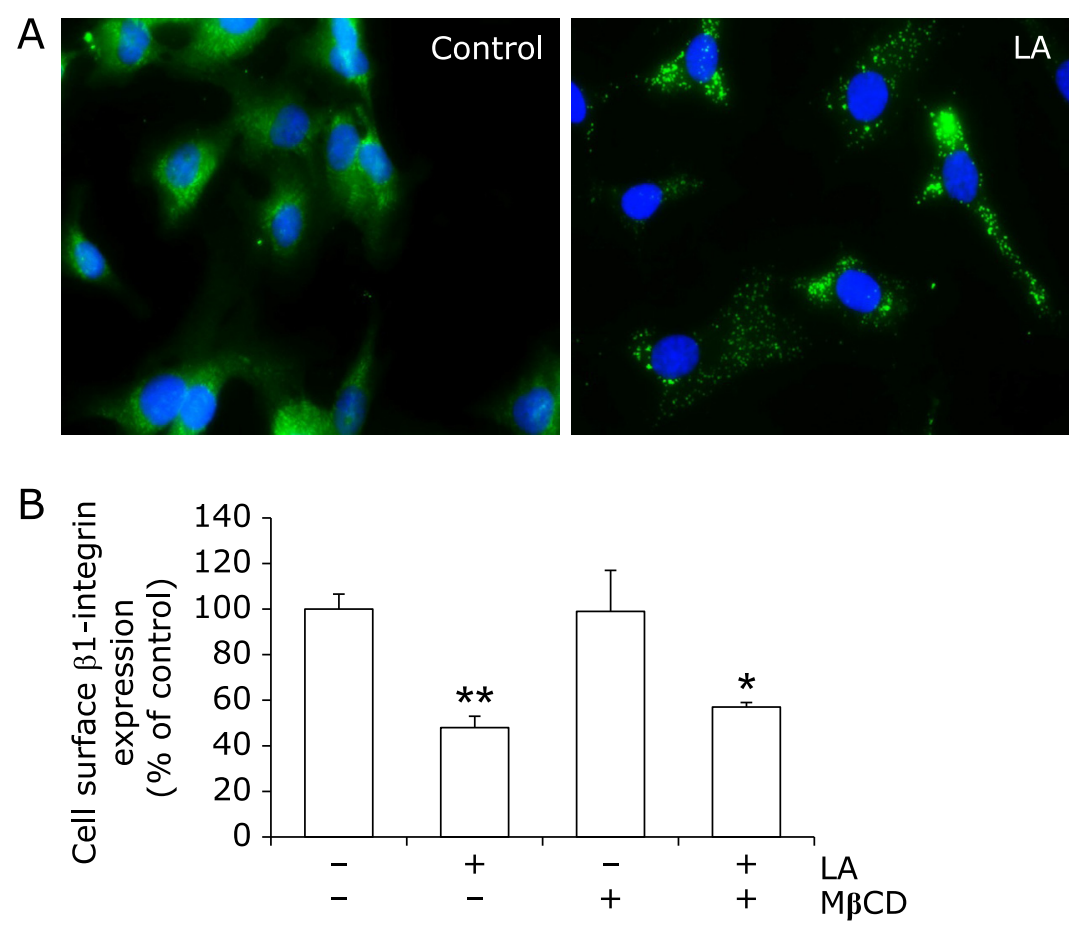

Fig. 6. $\quad \beta 1$-Integrin localization and role of raft in the action of $\alpha$-lipoic acid. (A) Cells were treated with $0,1.0 \mathrm{mM} \alpha$-lipoic acid (LA) for $48 \mathrm{~h}$ then $\beta 1$-integrin were stained with FITC-conjugated anti- $\beta 1$-integrin (green) and nucleus were stained with Hoechst 33342 (blue). (B) Cells were treated with or without $1.0 \mathrm{mM}$ LA and $1.0 \mathrm{mM} \mathrm{M} \beta C D$ for $24 \mathrm{~h}$ then cell surface $\beta 1$-integrin expression was detected. Results are means \pm SD of 3 samples. Values marked with asterisk(s) are significantly different from the control $(\mathrm{LA}(-), \mathrm{M} \beta C D(-))$ value at ${ }^{*} p<0.05$ and $* * p<0.01$, respectively. M $\beta C D$; methyl $\beta$-cyclodextrin.

putative molecular target of LA has been unclear. This report presents novel effect of LA on the bladder cancer cells and the importance of $\beta 1$-integrin in the action of LA. From clinical point of view, $\beta 1$-integrin suppression is significant because engagement of integrin on ECM provokes resistance to cancer drugs. T24 cells highly express $\beta 1$-integrin that is largely responsible for adhesion to fibronectin and acquire drug resistance to mitomycinC via PI3K/Akt pathway. ${ }^{(56-58)}$ Therefore LA might be useful for sensitizing bladder cancer cells to anticancer drugs.

\section{Acknowledgments}

This work is supported by Grand-in Aid Scientific Research (C) No. 20580137.

\section{References}

1 Bamford S, Dawson E, Forbes S, et al. The COSMIC (Catalogue of Somatic Mutations in Cancer) database and website. Br J Cancer 2004; 91: 355-358.

2 Karnoub AE, Weinberg RA. Ras oncogenes: split personalities. Nat Rev Mol Cell Biol 2008; 9: 517-531.

3 Schubbert S, Shannon K, Bollag G. Hyperactive Ras in developmental disorders and cancer. Nat Rev Canser 2007; 7: 295-308.

4 Irani K, Xia Y, Zweier JL, et al. Mitogenic signaling mediated by oxidants in Ras-transformed fibroblasts. Science 1997; 275: 1649-1652.

5 Zaitsu H, Tanaka H, Mitsudomi T, Matsuzaki A, Ohtsu M, Kimura G. Differences in proliferation properties among sublines of rat $3 \mathrm{Y} 1$ fibroblasts transformed by various agents in vitro. Biomed Res 1998; 9: 181-197.

6 Yamasaki M, Omi Y, Fujii N, et al. Mustard oil in "Shibori Daikon" a variety of Japanese radish, selectively inhibits the proliferation of H-ras-transformed 3 Y1 cells. Biosci Biotechnol Biochem 2009; 73: 2217-2221.

7 Yamasaki M, Iwase M, Kawano K, Sakakibara Y, Suiko M, Nishiyama K. Alpha lipoic acid selectively inhibits proliferation and adhesion to fibronectin

\section{Abbreviations}

DMEM Dulbecco's modified Eagle's medium

ECMs extracellular matrixes

FAK focal adhesion kinase

FBS fetal bovine serum

LA $\quad \alpha$-lipoic acid

M $\beta C D \quad$ methyl $\beta$-cyclo dextrin

MMP matrix metalloproteinase

PBS phosphate buffered saline

TTBS Tris-buffered saline with $0.1 \%$ Tween-20

\section{Conflict of Interest}

No potential conflicts of interest were disclosed. of v-H-ras-transformed 3Y1 cells. J Clin Biochem Nutr 2012; 50: 234-240.

8 Yamasaki M, Kawabe A, Nishimoto K, et al. Dihydro-alpha-lipoic acid has more potent cytotoxicity than alpha-lipoic acid. In Vitro Cell Dev Biol Anim 2009; 45: 275-280.

9 Simbula G, Columbano A, Ledda-Columbano GM, et al. Increased ROS generation and p53 activation in alpha-lipoic acid-induced apoptosis of hepatoma cells. Apoptosis 2007; 12: 113-123.

10 Wenzel U, Nickel A, Daniel H. Alpha-Lipoic acid induces apoptosis in human colon cancer cells by increasing mitochondrial respiration with a concomitant O2-*-generation. Apoptosis 2005; 10: 359-368.

11 Lee HS, Na MH, Kim WK. Alpha-Lipoic acid reduces matrix metalloproteinase activity in MDA-MB-231 human breast cancer cells. Nutr Res 2010; 30: 403-409.

12 Kiaris H, Spandidos D. Mutations of ras genes in human tumours (review) Int J Oncol 1995; 7: 413-421.

13 Adjei AA. Blocking oncogenic Ras signaling for cancer therapy. $J$ Natl 
Cancer Inst 2001; 93: 1062-1074.

14 Wang AX, Chang JW, Li CY, Liu K, Lin YL. H-ras mutation detection in bladder cancer by COLD-PCR analysis and direct sequencing. Urol Int 2012; 88: $350-357$.

15 Johne A, Roots I, Brockmöller J. A single nucleotide polymorphism in the human H-ras proto-oncogene determines the risk of urinary bladder cancer. Cancer Epidemiol Biomarkers Prev 2003; 12: 68-70.

16 Przybojewska B, Jagiello A, Jalmuzna P. H-RAS, K-RAS, and N-RAS gene activation in human bladder cancers. Cancer Genet Cytogenet 2000; 121: 7377.

17 Saito S, Hata M, Fukuyama R, et al. Screening of H-ras gene point mutations in 50 cases of bladder carcinoma. Int J Urol 1997; 4: 178-185.

18 Taparowsky E, Suard Y, Fasano O, Shimizu K, Goldfarb M, Wigler M. Activation of the T24 bladder carcinoma transforming gene is linked to a single amino acid change. Nature 1982; 300: 762-765.

19 Nista A, Mattioni M, Gismondi A, Palmieri G, Santoni A. Beta 1-Integrin expression and function in human bladder cancer cells: modulation by TNF alpha. Anticancer Res 1996; 16: 581-588.

20 Laidler P, Gil D, Pituch-Noworolska A, et al. Expression of beta1-integrins and N-cadherin in bladder cancer and melanoma cell lines. Acta Biochim Pol 2000; 47: 1159-1170.

21 Heyder C, Gloria-Maercker E, Hatzmann W, Niggemann B, Zänker KS, Dittmar T. Role of the beta1-integrin subunit in the adhesion, extravasation and migration of T24 human bladder carcinoma cells. Clin Exp Metastasis 2005; 22: 99-106.

22 Humphries MJ, Newham P. The structure of cell-adhesion molecules. Trends Cell Biol 1998; 8: 78-83.

23 Buccione R, Orth JD, McNiven MA. Foot and mouth: podosomes, invadopodia and circular dorsal ruffles. Nat Rev Mol Cell Biol 2004; 5: 647-657.

24 Mueller SC, Chen WT. Cellular invasion into matrix beads: localization of beta 1 integrins and fibronectin to the invadopodia. J Cell Sci 1991; 99: 213225.

25 Mierke CT, Frey B, Fellner M, Herrmann M, Fabry B. Integrin $\alpha 5 \beta 1$ facilitates cancer cell invasion through enhanced contractile forces. $J$ Cell Sci 2011; 124: 369-383.

26 Chan PY, Kanner SB, Whitney G, Aruffo A. A transmembrane-anchored chimeric focal adhesion kinase is constitutively activated and phosphorylated at tyrosine residues identical to pp125FAK. J Biol Chem 1994; 269: 2056720574.

27 Igishi T, Fukuhara S, Patel V, Katz BZ, Yamada KM, Gutkind JS. Divergent signaling pathways link focal adhesion kinase to mitogen-activated protein kinase cascades. Evidence for a role of paxillin in c-Jun $\mathrm{NH}(2)$-terminal kinase activation. J Biol Chem 1999; 274: 30738-30746.

28 Marracci GH, McKeon GP, Marquardt WE, Winter RW, Riscoe MK, Bourdette DN. Alpha lipoic acid inhibits human T-cell migration: implications for multiple sclerosis. J Neurosci Res 2004; 78: 362-370.

29 Thamilselvan V, Craig DH, Basson MD. FAK association with multiple signal proteins mediates pressure-induced colon cancer cell adhesion via a Src-dependent PI3K/Akt pathway. FASEB J 2007; 21: 1730-1741.

30 Bouchard V, Demers MJ, Thibodeau S, et al. Fak/Src signaling in human intestinal epithelial cell survival and anoikis: differentiation state-specific uncoupling with the PI3-K/Akt-1 and MEK/Erk pathways. J Cell Physiol 2007; 212: 717-728.

31 Marracci GH, Jones RE, McKeon GP, Bourdette DN. Alpha lipoic acid inhibits $\mathrm{T}$ cell migration into the spinal cord and suppresses and treats experimental autoimmune encephalomyelitis. J Neuroimmunol 2002; 131: 104-114.

32 Parsons JT, Martin KH, Slack JK, Taylor JM, Weed SA. Focal adhesion kinase: a regulator of focal adhesion dynamics and cell movement. Oncogene 2000; 19: 5606-5613.

33 Schmidmaier R, Baumann P. ANTI-ADHESION evolves to a promising therapeutic concept in oncology. Curr Med Chem 2008; 15: 978-990.

34 Bustelo XR, Sauzeau V, Berenjeno IM. GTP-binding proteins of the Rho/Rac family: regulation, effectors and functions in vivo. Bioessays 2007; 29: 356370.

35 Schwartz L, Abolhassani M, Guais A, et al. A combination of alpha lipoic acid and calcium hydroxycitrate is efficient against mouse cancer models: preliminary results. Oncol Rep 2010; 23: 1407-1416.

36 Guais A, Baronzio G, Sanders E, et al. Adding a combination of hydroxycitrate and lipoic acid (METABLOC ${ }^{\mathrm{TM}}$ ) to chemotherapy improves effectiveness against tumor development: experimental results and case report. Invest
New Drugs 2012; 30: 200-211.

37 Dominguez-Escrig JL, Kelly JD, Neal DE, King SM, Davies BR. Evaluation of the therapeutic potential of the epidermal growth factor receptor tyrosine kinase inhibitor gefitinib in preclinical models of bladder cancer. Clin Cancer Res 2004; 10: 4874-4884.

38 Min AK, Kim MK, Seo HY, et al. Alpha-lipoic acid inhibits hepatic PAI-1 expression and fibrosis by inhibiting the TGF-beta signaling pathway. Biochem Biophys Res Commun 2010; 393: 536-541.

39 Lee WR, Kim A, Kim KS, et al. Alpha-lipoic acid attenuates atherosclerotic lesions and inhibits proliferation of vascular smooth muscle cells through targeting of the Ras/MEK/ERK signaling pathway. Mol Biol Rep 2012; 39: 6857-6866.

40 Hughes PE, Renshaw MW, Pfaff M, et al. Suppression of integrin activation: a novel function of a Ras/Raf-initiated MAP kinase pathway. Cell 1997; 88: 521-530.

41 Hughes PE, Oertli B, Hansen M, Chou FL, Willumsen BM, Ginsberg MH. Suppression of integrin activation by activated Ras or Raf does not correlate with bulk activation of ERK MAP kinase. Mol Biol Cell 2002; 13: 22562265.

42 Gahmberg CG, Fagerholm SC, Nurmi SM, Chavakis T, Marchesan S, Grönholm M. Regulation of integrin activity and signalling. Biochim Biophys Acta 2009; 1790: 431-444

43 Pocheć E, Lityńska A, Bubka M, Amoresano A, Casbarra A. Characterization of the oligosaccharide component of alpha3betal integrin from human bladder carcinoma cell line T24 and its role in adhesion and migration. Eur $J$ Cell Biol 2006; 85: 47-57.

44 del Pozo MA, Alderson NB, Kiosses WB, Chiang HH, Anderson RG, Schwartz MA. Integrins regulate Rac targeting by internalization of membrane domains. Science 2004; 303: 839-842.

45 Cheng ZJ, Singh RD, Sharma DK, et al. Distinct mechanisms of clathrinindependent endocytosis have unique sphingolipid requirements. Mol Biol Cell 2006; 17: 3197-3210.

46 Palazzo AF, Eng CH, Schlaepfer DD, Marcantonio EE, Gundersen GG. Localized stabilization of microtubules by integrin- and FAK-facilitated Rho signaling. Science 2004; 303: 836-839.

47 Ren XD, Wang R, Li Q, Kahek LA, Kaibuchi K, Clark RA. Clark Disruption of Rho signal transduction upon cell detachment. J Cell Sci 2004; 117: $3511-$ 3518.

48 Echarri A, Muriel O, Del Pozo MA. Intracellular trafficking of raft/caveolae domains: insights from integrin signaling. Semin Cell Dev Biol 2007; 18: 627-637.

49 Gu Z, Noss EH, Hsu VW, Brenner MB. Integrins traffic rapidly via circular dorsal ruffles and macropinocytosis during stimulated cell migration. $J$ Cell Biol 2011; 193: 61-70.

50 Caswell P, Norman J. Endocytic transport of integrins during cell migration and invasion. Trends Cell Biol 2008; 18: 257-263.

51 Boyd ND, Chan BM, Petersen NO. Betal integrins are distributed in adhesion structures with fibronectin and caveolin and in coated pits. Biochem Cell Biol 2003; 81: 335-348.

52 Panicker AK, Buhusi M, Erickson A, Maness PF. Endocytosis of beta1 integrins is an early event in migration promoted by the cell adhesion molecule L1. Exp Cell Res 2006; 312: 299-307.

53 Sharma DK, Brown JC, Cheng Z, Holicky EL, Marks DL, Pagano RE. The glycosphingolipid, lactosylceramide, regulates beta1-integrin clustering and endocytosis. Cancer Res 2005; 65: 8233-8241.

54 Thorne RF, Marshall JF, Shafren DR, Gibson PG, Hart IR, Burns GF. The integrins alpha3beta1 and alpha6beta1 physically and functionally associate with CD36 in human melanoma cells. Requirement for the extracellular domain of CD36. J Biol Chem 2000; 275: 35264-35275.

55 Vassilieva EV, Gerner-Smidt K, Ivanov AI, Nusrat A. Lipid rafts mediate internalization of betal-integrin in migrating intestinal epithelial cells. $\mathrm{Am} \mathrm{J}$ Physiol Gastrointest Liver Physiol 2008; 295: G965-G976.

56 Zhang CJ, Shen ZJ, Pan CW, Zhong S, Li T, Zhang MG. Engagement of integrin $\beta 1$ induces resistance of bladder cancer cells to mitomycin-C. Urology 2012; 79: 638-643.

57 Saito T, Kimura M, Kawasaki T, Sato S, Tomita Y. Correlation between integrin alpha 5 expression and the malignant phenotype of transitional cell carcinoma. Br J Cancer 1996; 73: 327-331.

58 Pan $\mathrm{CW}$, Shen ZJ, Wu TT, et al. Cell adhesion to fibronectin induces mitomycin C resistance in bladder cancer cells. BJU Int 2009; 104: 1774-1779. 